\title{
The Research on Cooperative Learning in English Reading Teaching in College
}

\author{
Yayan $\mathrm{Yu}$ \\ Shanxi Normal University, China
}

\begin{abstract}
There are four basic skills in English learning, namely, listening, speaking, reading and writing, while reading is the most fundamental and important skill. It is also the main and effective way to learn English, so improving the quality of reading teaching is the key to improve the quality of foreign language teaching. However, in traditional teacher-centered teaching method, students gain knowledge passively and cannot effectively show their personality and abilities.

Cooperative learning is a new strategy in English teaching, which can make improvement by the application of interactive teaching dynamic factors, so cooperative learning is an effective way to solve the problems in education. Data analysis points out that cooperative learning strongly promotes the efficiency and has good prospects for development. The study also finds out the problems in the application of cooperative learning in English reading practice.
\end{abstract}

Index Terms - Cooperative learning; College English, English reading, Reading teaching

\section{INTRODUCTION}

With the development of economy and technology, the pace of globalization is very fast and the communication with foreign countries grows frequently. The college educational system faces a huge challenge.

As an international language, English plays a more and more important role, so English teaching received more and more attention in China. Thus, an effective English teaching approach for English learning is in urgent need. However, the traditional teacher-centered method neglects it. In a traditional English reading class, the students have few chances to participate in real communication. When the teachers teach the reading parts, they just explain or translate the sentences word by word. And the teacher is the center of class, students only need to sit and take notes and memorize what the teacher has taught. In the traditional method, the students need to meet the requirements of language education, so they just work independently and compete for good scores without cooperation. In the class, the teachers focus on the scores rather than the process of learning. So this system has bad effects and cannot improve students' learning ability.

Cooperative learning is one of the most creative and successful instructional approaches. It is an instructional strategy in the United States in the early 1970s. The researchers pay more attention to cooperative learning because of the proven effectiveness. The cooperative learning based on the group work emphasizes that the students accomplish one goal together. Making joint effort to accomplish the aim in groups is the core notion of the cooperative learning.

In order to overcome the shortcomings of traditional English teaching, cooperative learning has been brought into China. Many researches have proved the importance of cooperative learning in reading classes in college. The purpose of this research is to prove that cooperative learning can improve student's reading ability, and has a positive effect on the students' motivation, confidence, lowering anxiety, and learning atmosphere. What is more, there are still some problems in cooperative learning.

This paper is made up of six parts. Part one is about the background, significance and organization of the research. Part two is to introduce the definitions of cooperative learning, and the related research of cooperative learning at home and abroad. The research design is presented in the third part, and it includes research questions, research subjects, research instruments and procedure. Part four is about data analysis. Part five shows some findings in the study. Finally the author draws the conclusion of the paper.

\section{LITERATURE REVIEW}

\section{A. The Definition of Cooperative Learning}

Cooperative learning is one of the most creative and successful instructional approaches in the history of education and arose in the early 1970s in America. As a new attempt, it emphasized the student - student interaction. When it appeared, there were many scholars who promoted the idea into practice. They defined cooperative learning according to their own thought and understanding but they were similar.

Slavin (1987) defined cooperative learning in this way: "instructional methods in which students of all performance levels work together in small groups toward a group goal". The feature of this definition is that let one student help other students when they are in difficult situations. The cooperative learning is based on the group work and it aims to accomplish one common goal rather than individual's tasks. The core notion of the cooperative learning is to make great 
effort to accomplish the aim in groups.

In China, the main representative of cooperative learning is Wang Tan (2001), and he defined cooperative learning as a systematic teaching strategy that make students learn to cooperate in heterogeneous teams towards a common goal and is rewarded based on the success of the team. The research and practice of cooperative learning marked that the cooperative learning has matured gradually in China.

In the view of above, cooperative learning is one of the teaching methods which proceeds in group activities, thus all members of the group can make progress together. Within a cooperative group, each group member can learn from each other. They participate in activities positively in order to achieve a common goal.

\section{B. The Elements of Cooperative Learning}

Each researcher has their own understanding of the elements of CL. So there are many elements of cooperative learning. At present, we all know five essential elements: positive interdependence, individual accountability, face-to-face group interaction, development of small group social skills and group processing.

1. Positive Interdependence

As the first and foremost element, "one for all, all for one "is a direct description for positive interdependence, which means the members on the same boat need to share resources and there is no prejudice, and everyone can get the same things. The members are reliant on each other and they should realize they have the common goal, and they should help others and work together to achieve the common goal.

2. Individual Accountability

Individual accountability refers to that the members must take their efforts to accomplish individual tasks which are assigned by groups. They should have a responsibility to participate in the activity for the success of the group. When every member deals with their own task, they should be responsible for the goal.

3. Face-to-Face Group Interaction

There is positive interdependence, and there is face-to-face group interaction. The face-to-face group interaction can directly help the groups succeed. The members have the opportunity to listen to and express and figure out what their weaknesses are by discussing face-to-face. And they can share resources and knowledge, interpret solutions to the question and discuss the native of concepts they have learned, and finally make progress together.

4. Development of Small Group Social Skills

Social skills are also an important element in CL. There are many social skills that the members should learn such as leadership, decision-making, trust-building communication and conflict-management skills. When the cooperative groups want to get success or to have a high quality production, individual not only needs to learn linguistic knowledge but also social skills.

5. Group Processing

Group processing results from the reflection and discussion of the group's experience. We can regard it as a plan that each member must obey. Group processing makes clear steps to achieve their goals. They can change the steps when they think they are not suitable. By this way, group processing helps to ensure the effectiveness of the team work.

\section{The Major Approaches of Cooperative Learning}

In history, there are kinds of cooperative activities which have been provided, and many researchers put forward a lot of approaches of cooperative learning. The cooperative learning requires the existence of a group, so four typical classroom groups have developed and have been used in practice.

1. Student Team-Achievement Divisions (STAD)

STAD has been put into practice widely in many fields, such as mathematics, languages arts and social sciences and etc. It is suitable for the teaching which has a correct answer and a clear teaching goal. In STAD (Slavin, 1987), according to performance level, sex, and ethnicity, students are assigned to four-member learning teams to grasp the knowledge and skills. Firstly the teacher presents a lesson, and then students learn the knowledge within their teams to make sure that all team members have mastered the lesson. Finally, all students take individual quizzes, and they may not help one another.

STAD implies a main idea that is to stimulate students to encourage and help each other to master the lesson. When they work together, they can communicate and discuss with each other.

2. Team-Games-Tournament (TGT)

In this activity, it uses the same teaching method and group activities as STAD, except that they compete once a week between groups instead of taking individual quizzes. Each member makes their efforts to compete in order to win the competition for their team. Finally the winning team gets the reward.

Comparing with STAD, this kind of team-work is funnier because of the interesting competition. The team members solve the problems together and help each other to prepare for the competition. In this process, they can ensure the implementation of individual responsibility.

3. Jigsaw II

The jigsaw method is one of the most effective cooperative methods that can improve students' self-esteem and emphasize students' interdependence. Each student has to rely on other group mates' information to complete the required task. 
Jigsaw II method is an adaptation of Aronson's jigsaw approach. Jigsaw II assigns different tasks based on the same material. The members are required to hand in essay or give oral report. In jigsaw II method, students work in heterogeneous teams. They are divided into parts to read materials, and students are given expert sheets which contain different topics and each team member should focus on the topics while reading. When everyone has finished reading, students from different teams with the same topic discuss their topics for about 30 minutes. The teaching process of jigsaw II method consists of five steps: material reading, expert group discussion, jigsaw group discussion, testing, and group recognition.

4. Group Investigation (CI)

GI was developed by Sharan (1992), and it is the student group method. In this method, a general topic is first brought forward by the teacher. Students are divided into different groups. Different groups are assigned different tasks or different aspects of the same topic. Each group is responsible for their own learning, and they gather information, analyze the data, synthesize their findings and present their final report to the whole class. In this process, students must accomplish the task by themselves while depending on each other to solve the emerging problems.

To sum up, GI involves six steps as follows: (a) identifying the topic and organizing students into research groups; (b) planning the learning tasks; (c) carrying out the investigation; (d) preparing for the final report; (e) presenting the final report; (f) evaluation.

\section{Related Research at Home and Abroad}

Cooperative learning has covered a long period of development since the $19^{\text {th }}$ and $20^{\text {th }}$ century. In ancient Rome, some educationalists believed that students could reap benefits by learning from each other, which emphasized the interaction among students. In 1806, the cooperative learning was introduced into the USA and drew attention from the famous educationalists such as Francis Parker and John Dewey. And then they widely used it in practice. Then cooperative learning has become a part of the teaching method.

From the late 1960s to the mid of 1970s, cooperative learning made substantial progress and developed into an innovative and influential system of instructional theory and strategy. In 1970s, cooperative learning started in America as an effective teaching theory and strategy. Lots of effective and successful strategies on it come out by many experiments. Furthermore, many subjects have applied cooperative learning strategies for the sake of its various specific methods. Many educationists have made lots of experimental researches to devote themselves to the development of it. So Cooperative Learning Method is widely used in almost every elementary and secondary school and many colleges and universities of many countries, such as America, Israel, Canada, Britain, Germany, Australia and Japan.

In recent decades, many educators abroad have been researching on cooperative learning. They all proclaimed that students could make great progress in their study with communication and cooperation.

Since the late 1980s, Cooperative Learning has been introduced in China, and the perspective of theory and practice were discussed. But it is still quite a new concept to Chinese education field. Many scholars focus on this new teaching strategy and research the conception of cooperative learning in history, and it influenced the education and attracted the attention of the world. Many scholars make the research on Cooperative Learning, for example, Wang Tan, who elaborates on its historical development, theoretical underpinning, principles, strategies, comment, empirical studies and so on. The earlier attempt of applying cooperative learning carried out by the Hang Zhou University, Tianchang Middle School and No.1 Middle School of Hang Zhou. The teachers of the experimental classes said that cooperative learning in small groups could add vitality and dynamic to the class. Another important and typical experiment which used cooperative learning and practice was conducted in Shan Dong province in 1993. It covered more than 100 schools, ranging from preschool to college and was supported by many Chinese and foreigners. Later, a series of studies of cooperative learning in English classroom followed. And cooperative learning has made many changes in students' achievement, learning environment and learning attitudes.

And there are many researchers, such as Pei Dina (2000) declares that cooperative learning makes contribution to students' academic ability, makes them adapt to the society better in the future, and cultivates the autonomy learning ability. Wang Liang (2006) stated that cooperative learning had the advantages of improving the students' learning qualities and awareness.

\section{RESEARCH DESIGN}

Researchers have done a number of studies on cooperative learning in the foreign countries and they have proved the effectiveness of cooperative learning in language learning, and a lot of Chinese researchers also have proved its effectiveness in English teaching. Based on the above discussion of Cooperative Learning, the paper here is to explore students' attitudes to the English reading and examine the effectiveness of Cooperative Leaning in reading teaching in college.

\section{A. Research Questions}

This paper displays an experimental study of cooperative learning in English reading class in college, which aims to explore the following aspects:

(1) Can cooperative learning improve students' reading ability? 
(2) Can cooperative learning have a positive effect on the students' motivation, confidence, learning interest, and learning atmosphere?

(3) What problems still exist in cooperative learning?

\section{B. Research Subjects}

The experiment is conducted from September 2014 to December 2014. And the participants of research are from two classes of Grade Three (Class 1 and Class 2)in North University of China in Taiyuan district, Shanxi province. The two classes are parallel classes of similar level. All of them come from different families and schooling backgrounds. One class (Class 1) is randomly chosen as the experimental class, and the other class (Class 2) is the controlled class. These two classes are almost at the same level in terms of their reading competence according to their achievements in the pretest. They share the same teacher.

TABLE I.

INFORMATION ABOUT THE SUBJECTS

\begin{tabular}{|c|c|c|c|c|}
\hline Class & Number & Male & Female & $\begin{array}{c}\text { Average } \\
\text { Age }\end{array}$ \\
\hline Class 1(EC) & 42 & 22 & 20 & 21 \\
\hline Class 2(CC) & 42 & 21 & 21 & 22 \\
\hline
\end{tabular}

\section{Research Instruments and Procedures}

\section{Instruments}

The author takes effort to make the experiment as practical and persuasive as possible, so the instruments used in the research are: two reading comprehension tests, one questionnaire and one open interview.

\section{Procedures}

This section describes six steps of implementing cooperative learning in English reading teaching. They are preparation, talk-design, pre-reading, while reading, post-reading and evaluation.

(1) Preparation

The preparation consists of clarifying cooperative learning to the students, group formation, clarifying student roles and team training before the implementation of cooperative learning. And before the research, all students should attend the first reading comprehension test and answer the questions in questionnaire in September, 2014. The data of the questionnaire were collected and analyzed for the preparation.

42 students in each class were divided into seven groups, and each group had six members. And each group consisted of high-achieving, medium-achieving and low-achieving students. After the groups were assigned, each member would take different specific roles in different tasks.

Previous researches suggest that cooperative groups should be as small as possible to make it easier to interact. One group formation should have six roles: an organizer, a recorder, a summarizer, a challenger, an evaluator and a storyteller. An organizer should ensure the smooth process of cooperative learning; a recorder should take down what the group members explain and discuss; a summarizer should deliver a speech about team considerations, conclusions and recommendations; a challenger should reflect an opposing view to increase the creative ideas in a dialogue; an elevator should give assessment for peer group work performance; a storyteller should convey examples that help to deepen the understanding. After dividing each class into seven groups, the author clarified student roles to everyone.

Finally, the author thought it was of great importance that the students should be trained at the beginning of the experiment. Students should understand the detail of cooperative learning and how to cooperate with members. During this period, first, the researcher gave detailed explanations about cooperative learning. Students should make clear that they are responsible for their team. They should work towards a common goal and they were not allowed to help each other in the test. All the members could finish the task when they all had grasped the assigned material. In addition, they could develop some social skills. During the training period, they could learn some model researches so that they could apply these skills easily.

(2) Task-design

In order to achieve the success of cooperative learning, teachers should take students' capability of accepting new knowledge into account. When teachers design the task, they should go from simple objectives to difficult ones. Besides, according to Shavelson and Stem (1981:478), task-design should take the following steps:

a. content: the subject matter to be taught

b. materials: the things that learners can observe, manipulate

c. activities: the things the learners and teacher will be doing during the lesson

d. goals: the teacher's general aims for the task

e. students---their abilities, needs and interests

f. community----the class as a whole and its sense of "groupness"

In conclusion, when teachers design the task, they should take students' needs, interest, language ability and cognitive level into account. They should conform to the principle-learning-by-doing. It can arouse students' interest and enthusiasm in language learning. Above all, the author thinks that the teacher is supposed to play a good role in 
supporting and instructing students in the whole process of English learning.

(3) Pre-reading

In this stage, cooperative learning strategies were adopted flexibly according to different learning materials and activities. Students should understand the procedures that they should follow. After the teacher introduced the topic with background knowledge and made sure that the students understand the task, students should collect information about the title, preview the new words, phrases, and read the passage. After that, the researcher assigned the task to each member of groups and got them ready for group activities.

Firstly, when the teacher lead-in the topic, they can give them some questions, for example, what is the text mainly about? What is the main idea of this passage? What do you know about the author? In this task, pictures, videos, or some other materials were shown to the students. In order to improve students' interests in learning English as well, the teacher can ask the students to act out role-plays. Students can have a good knowledge of the topic-related information by doing that. The members can express their points of view respectively about the background of the title. Besides, other activities can be taken in the lesson, such as jigsaw, group investigation, asking and answering, reporting, storytelling, guessing, playing games and filling in the blanks.

Secondly, vocabulary learning is a very important task in the pre-reading. In this task, students should learn together in groups. Each of them had a sense of responsibility for their group learning, and they can be assigned by different words and everyone could refer to the dictionary for one part then they gather to share what they have learned about their own words. It includes the pronunciation, usage of words and some sentence examples. Finally, all groups could exchange their ideas and correct the errors which other groups had made. Then the teacher could give an explanation to students to work out difficult points.

(4) While-reading

In this stage, reading comprehension is the key point. In the reading test, there are many questions such as predicting, word guessing, asking the style of the text, finding the main idea and writer's purpose, analyzing the structure and summarizing. In order to practice their reading skills, students could finish the exercises by skimming, scanning, summarizing, inferring or guessing the meaning of the words from the context on their own. After that, teacher could ask some questions to each student to present their ideas. For example:

a. What's the main idea of this passage?

b. What is the structure of the passage?

c. Can you guess the word in the three paragraphs by scribbling?

d. According to the passage which of the following statements is true?

e. What is the writer's purpose?

In this stage, Jigsaw was a proper method to accomplish the questions. Students were divided into several parts and each member was responsible for one part. The students in different groups who had the same question could gather to form an expert team to share their ideas and they could write down what the other said, and then put forward the difficulties to the teacher to solve the difficulties. Then they went back to their group to share other group members' idea. At last, a test was given to the students.

(5) Post-reading

In cooperative learning in English reading, every member's performance has a great effect on the achievement of the group, so the students are asked to be active, serious and confident. After reading, the students might have a discussion to exchange their ideas to get the main idea of the passage and some detailed information, or they can have a debate speech to achieve their goals. Then they choose the best answer to the researcher. Finally, the excellent group has the chance to show their achievements and atmosphere. The star of the group of the highest score can be rewarded.

(6) Evaluation

After reading, the teacher should evaluate each group timely and gave feedback to their performance. There were seven groups in each class and each group had six members. The students should attend the second reading comprehension test and answer the questions to check how much the students had mastered. According to the examinations for the evaluation of cooperative learning, the research might give a score to each group. Each member in the group was evaluated by their own performance and they might give a score to themselves. Finally, each student would answer the questions again.

After the experiment, eight students were chosen randomly from EC to ask them about their thoughts before and after a term of cooperative learning. When the researcher builds a face-to-face interview, we can know more objectively about their problems in cooperative learning in a large class.

\section{Data Collection}

In order to investigate whether cooperative learning can improve students' reading ability, the author uses pre-test, post-test and questionnaire to collect data. In the reading test, the author gives out 84 copies, 79 of them are valid in the pre-test and 78 of them are valid in the post-test. In addition, the questionnaires are given out 84 copies before the experiment and 80 of them are valid, and the author gives out 42 after the experiment in the experiment class and 40 of them are valid.

\section{RESUltS AND DisCUSSION}




\section{A. Analysis of Tests}

In the pre-test, the researcher collected the data of students' English reading scores to analyze the differences data between two classes. The result is shown in the following table.

TABLE II

ANALYSIS OF THE FIRST READING COMPREHENSION TEST(PRE-TEST)

\begin{tabular}{|c|c|c|}
\hline Class & Number & Mean \\
\hline Class1(EC) & 39 & 68.5 \\
\hline Class2(CC) & 40 & 69.1 \\
\hline
\end{tabular}

From Table 4.1, we can see that there was no significant difference between two classes, and the two classes have similar English reading level before they take part in the experiment. So the author just chose class one randomly as experimental class, the other as controlled class.

TABLE III

ANALYSIS OF THE SECOND READING COMPREHENSION TEST (POST-TEST)

\begin{tabular}{|c|c|c|}
\hline Class & Number & Mean \\
\hline Class1(EC) & 39 & 82.5 \\
\hline Class2(CC) & 39 & 68.1 \\
\hline
\end{tabular}

From Table 4.2, we can see that there exists an obvious difference between their scores after the experiment. During the experiment, the author used the traditional teaching method in controlled class and the cooperative learning in experimental class. This result proves cooperative learning can help students improve their reading competence in class and develop their reading abilities.

\section{B. Analysis of Questionnaires}

Discussion of Questionnaire before Experiment

At the beginning of the experiment, 84 students are asked to fill out questionnaire, and they must be honest and careful to finish it. They can choose the suitable choice for themselves from the 10 items in the questionnaire. The following table displays the outcome of the questionnaire.

TABLE IV.

THE RESULT OF QUESTIONNAIRE BEFORE EXPERIMENT

( $\mathrm{EC}=$ experimental class; $\mathrm{CC}=$ control class; $\mathrm{A}, \mathrm{B}, \mathrm{C}$ choice items; $\mathrm{P}=$ percentage)

\begin{tabular}{|c|c|c|c|c|}
\hline Item & Class & $\mathrm{A}(\%)$ & $\mathrm{B}(\%)$ & $\mathrm{C}(\%)$ \\
\hline \multirow[t]{2}{*}{1} & EC & 20.5 & 50.37 & 29.13 \\
\hline & $\mathrm{CC}$ & 20.55 & 53.45 & 26 \\
\hline \multirow[t]{2}{*}{2} & $\mathrm{EC}$ & 24.2 & 31.6 & 44.2 \\
\hline & $\mathrm{CC}$ & 23.3 & 30.5 & 46.2 \\
\hline \multirow[t]{2}{*}{3} & $\mathrm{EC}$ & 24.4 & 26.2 & 49.4 \\
\hline & $\mathrm{CC}$ & 25.3 & 25.2 & 49.5 \\
\hline \multirow[t]{2}{*}{4} & $\mathrm{EC}$ & 16.5 & 45 & 43.5 \\
\hline & $\mathrm{CC}$ & 15 & 43.5 & 45 \\
\hline \multirow[t]{2}{*}{5} & $\mathrm{EC}$ & 13.5 & 32.5 & 54 \\
\hline & $\mathrm{CC}$ & 16.5 & 31.5 & 52 \\
\hline \multirow[t]{2}{*}{6} & $\mathrm{EC}$ & 10.5 & 50.4 & 39.1 \\
\hline & $\mathrm{CC}$ & 9.3 & 49.4 & 41.3 \\
\hline \multirow[t]{2}{*}{7} & $\mathrm{EC}$ & 11.5 & 29.3 & 59.2 \\
\hline & $\mathrm{CC}$ & 10.3 & 30.5 & 60.2 \\
\hline \multirow[t]{2}{*}{8} & $\mathrm{EC}$ & 17.5 & 25.5 & 57 \\
\hline & $\mathrm{CC}$ & 16.5 & 25.5 & 58 \\
\hline \multirow[t]{2}{*}{9} & $\mathrm{EC}$ & 24.8 & 20.7 & 64.5 \\
\hline & $\mathrm{CC}$ & 24.7 & 21.5 & 63.8 \\
\hline \multirow[t]{2}{*}{10} & $\mathrm{EC}$ & 32.5 & 10.6 & 56.9 \\
\hline & $\mathrm{CC}$ & 33.6 & 12.7 & 53.7 \\
\hline
\end{tabular}

From the Table 4.3, the result of the two class were almost the same. The questions 1 to 5 are intended to know students' reading ability and their attitude towards CL. Obviously in item 1, nearly $50.37 \%$ of the students both in the two class think it is not important to build the cooperative learning in English reading class; as far as the result in item 2 is concerned, approximately $45 \%$ of students think they don't support cooperative learning; from question 3, nearly half of the students considered cooperative learning useless in English reading; only a small of the students think their reading speed is very fast, and nearly $80 \%$ of them think their reading speed is slow in item 4 . It revealed that $85 \%$ of students think they do not have a deep understanding of English from item 5. So we can conclude from the above analyses that students' reading ability is not good.

The questions 6 to10 are intended to find out the present situation of students' reading learning. Obviously in item 6 , the above analyses show that nearly half of the students considered the atmosphere monotonous and nearly $40 \%$ of them think it is tense and oppressive; Data in item 7 exposed that in reading class many students suffered a lot of 
anxiety, who had no or little confidence in English reading, and the number can be up to 90\%; Item 8 is designed to know how most students perform in class. Half of the students are afraid to answer questions, and a quarter of the students just listened but were not willing to answer questions. Only a small number of them enjoyed answering questions actively; from the item 9, when other students spoke, about 65\% of the students did not listen and then gave up; item 10 revealed that only $10 \%$ of students are willing to participate in the activities. The above analyses show that many students don't have much interest and enough confidence in reading. When they do the reading exercise, they suffer a lot of anxiety. They are not willing to participate in the activities or answer questions.

The same questionnaire was conducted in the experimental class at the end of the experiment, and the following data were collected from the students' answers to the 10 items in the questionnaire.

TABLE V

THE RESUlTS OF THE QUESTIONNAIRE IN EC AFTER EXPERIMENT

\begin{tabular}{|c|c|c|c|c|}
\hline Item & Class & $\mathrm{A}(\%)$ & $\mathrm{B}(\%)$ & $\mathrm{C}(\%)$ \\
\hline 1 & $\mathrm{EC}$ & 89 & 11 & 0 \\
\hline 2 & $\mathrm{EC}$ & 11 & 88 & 1 \\
\hline 3 & $\mathrm{EC}$ & 90 & 9 & 1 \\
\hline 4 & $\mathrm{EC}$ & 69 & 22 & 9 \\
\hline 5 & $\mathrm{EC}$ & 65 & 25 & 10 \\
\hline 6 & $\mathrm{EC}$ & 75 & 13 & 12 \\
\hline 7 & $\mathrm{EC}$ & 57 & 39 & 4 \\
\hline 8 & $\mathrm{EC}$ & 16 & 84 & 0 \\
\hline 9 & $\mathrm{EC}$ & 77 & 19 & 4 \\
\hline 10 & $\mathrm{EC}$ & 80 & 15 & 5 \\
\hline
\end{tabular}

Table 4.4 shows that the cooperative learning can improve students' reading ability. Item 1 reveals that $89 \%$ of them think it is very important to build the cooperative learning in reading class; $88 \%$ of them like this method when they learn reading in item 2 ; in item 3,90\% of students considered cooperative learning can help them in English reading; and $66 \%$ of them think it has increased their reading speed in item 4; Item 5 revealed that $65 \%$ of students think they have a better understanding of English. In conclusion, the above analyses show that students' reading ability has improved by the cooperative learning.

Quite different from the results of questionnaire before the experiment, nearly all the students thought the classroom atmosphere was harmonious and relaxing in which they could learn actively, which revealed that cooperative learning helps create such a beneficial classroom atmosphere in the item 6; and from item 7, compared with the results of questionnaire before the experiment, a majority of the students claimed that their self confidence in English reading was strengthened; compared with their behavior before the experiment, $84 \%$ of the students performed much better in cooperative learning, and they were more willing to answer questions actively and voluntarily in item 8; from the item 9, when other students spoke, about $77 \%$ of the students are willing to listen to others; item 10 revealed that $80 \%$ of the students are willing to participate in the activities. So with the help of cooperative learning, they can understand questions more accurately and express ideas in group activities. Compared Table4.3 with Table4.4, it is obvious that cooperative learning has a positive effect on students' English reading. They indicate students can perform their parts as well as when learning in the cooperative way in reading class.

\section{Analysis of Interview}

From the interview, the students in the experimental class all proved the effectiveness of cooperative learning. But there are also some problems that students have put forward from the interview in the experimental class at the end of the experiment.

In the interview, five of eight students think when they are in cooperative activities, the class is much too noisy and four students think it is so disordered that students cannot hear each other clearly; four of them say some students make no effort but share the same outcomes. So working hard may have a negative feeling in learning. What's more, some of students say that they cannot communication in English.

\section{FINDINGS}

\section{A. The Benefits of Cooperative Learning}

After the two reading comprehension tests--two questionnaires and one open interview, the research proved that Cooperative learning has positive effect on the students' motivation, confidence, learning interest and learning atmosphere.

Firstly, it can provide much more opportunities for interaction and help to improve and develop their learning ability. In the cooperative learning, the teacher has more chance to contact with more students. By this way, the teachers can find more difficulties while students can learn in an interesting and dynamic situation. In the interaction, students can learn new concepts, knowledge and skills more easily. By organizing, planning and interacting, students can complete the learning tasks with their group members actively.

Secondly, it is a good method to improve students' integrated skills of language. The cooperative learning provides a 
good social environment where students can communicate with each other, discuss questions, ask and answer questions. By doing these, students' listening and speaking ability can be improved. When students read the general idea and detailed information, their reading skills can be improved. In addition, students must write down the result of discussions and write their answers on the blackboard. By this way, their writing ability can also be improved.

Thirdly, cooperative learning builds a relatively relaxing and harmonious learning environment. In the traditional English class, the students feel boring and they aren't willing to study. However, cooperative learning establishes a good learning atmosphere in which students can learn without anxiety but feel interested.

\section{B. The Problems in Cooperative Learning}

The author finds some problems in cooperative learning in the experiment.

Firstly, sometimes, it is too noisy and the class is disordered and students can not listen to each other clearly. It takes some time for them to get rid of the noise and excitement. This problem can deeply influence other groups' effectiveness.

Secondly, some students make no effort but share the same outcomes. Sometimes, some students may talk about something else. Some students have a desire for English learning, so they make efforts to complete the task, while others just play in the class.

Thirdly, some students can't communicate in English. The students have many difficulties in expressing their ideas in English throughout the whole group activity. Chinese is frequently used in group discussion. Because of the limitation in vocabulary and difficulties in expression, they sometimes use Chinese to express themselves, especially when they meet some complicated problems which are hard to explain clearly to their partners. They use Chinese instead. So in the cooperative leaning, it is very important to form a habit of communicating in English.

\section{CONCLUSION}

In this paper, the researcher has proved that cooperative learning is an effective method in English reading class. It has positive effect on the students' motivation, confidence, learning interest, and learning atmosphere. And this method creates a harmonious and comfortable learning environment. By doing various activities, the students have much more chances to communicate. However, there are some problems in the cooperative learning. As for the problems, here are some possible solutions.

Firstly, the researcher should build effective and systematic management to control the class, and the research can select a leader to manage the whole group.

Secondly, the researcher should make a clear concept of cooperative learning, which will help students develop their awareness of cooperative learning and make the members understand that the task is a team work. Everyone should try their best. Besides, the best performance should be rewarded and can accept the respect from the members.

Thirdly, in order to ensure that each member speak English, before the cooperative learning, the teacher should make the task suitable for the members. And when discussing, the members should help each other to speak English when someone has difficulties.

All in all, although the research about cooperative learning is not too long, it has great impact on English reading. It has given surprise to people both home and abroad. Researchers believe that the cooperative learning will bring a bright future with a long-field application and it will play an increasingly significant role in teaching system.

\section{ApPendiX A. The FIRst REAdING COMPREHENSION TEST}

Passage A

Women are also underrepresented in the administration and this is because there are so few women full professors. In 1985, Regent Beryl Wilburn produced a report blasting the University of Texas System administration for not encouraging women. The University was rated among the lowest for the system. In a 1987 update, Wilburn commended the progress that was made and called for even more improvement.

One of the positive results from her study was a system-wide program to inform women of available administrative jobs. College of Communication Associate Dean Patrica Weatherperson, said it is important that woman be flexible when it comes to relocating if they want to rise in the ranks.

Although a woman may face a chilly climate on campus, many times in order for her to succeed, she must rise above the problems around her and concentrate on her work.

Until women make up a greater percentage of the senior positions in the University and all academician equities will exist.

"Women need to spend their energies and time doing scholarly activities that are important here at the University." Spirituous said. "If they do that will be successful in this system. If they spend their time in little groups mourning the sexual discrimination that they think exists here, they are wasting valuable study time."

1. According to Spirituous, women need to

a. produce a report on sexual discrimination

b. call for further improvement in their working conditions 
c .spend their energies and time fighting against sexual discrimination

d. spend more time and energy doing scholarly activities

2. From this passage, we know that

a. there are many women full professors in the University of Texas

b. women play an important part in administrating the University

c. the weather on the campus is chilly

d. women make up a small percentage of the senior positions in the University

3. Which of the following statements is true?

a. the number of women professors in the University in 1987 was greater than that of 1985

b. the number of women professors in the University in 1987 was smaller than that of 1985

c. the number of women professors was the same as that of 1985

d. more and more women professors thought that sexual discrimination did exit in the University

4. One of the positive results from Wilburn's study was that

a. women were told to con cent rate on their work

b. women were given information about available administrative jobs

c. women were encouraged to take on all the administrative jobs in the University

d. women were encouraged to do more scholarly activities

5. The title for this passage should be

a. The University of Texas

b. Wilburn's Report

c. Women Professors

d. Sexual Discrimination in Academia

\section{ApPendix B. The SECOND CoMpreHENSION Test}

\section{Passage A}

There are three kinds of goals: short-term, medium-range and long-term goals.

Short-range goals are those that usually deal with current activities, which we can apply on a daily basis. Such goals can be achieved in a week or less, or two weeks, or possible months. It should be remembered that just as a building is no stronger than its foundation, out long-term goals cannot amount to very munch without the achievement of solid short-term goals. Upon completing our short-term goals, we should date the occasion and then add new short-term goals that will build on those that have been completed.

The intermediate goals build on the foundation of the short-range goals. They might deal with just one term of school or the entire school year, or they could even extend for several years. Any time you move a step at a time, you should never allow yourself to become discouraged or overwhelmed. As you complete each step, you will enforce the belief in your ability to grow ads succeed. And as your list of completion dates grow, your motivation and desire will increase.

Long-range goals may be related to our dreams of the future. They might cover five years or more. Life is not a static thing. We should never allow a long-term goal to limit us or our course of action.

1. Our long-term goals mean a lot

a. if we complete our short-range goals

b. if we cannot reach solid short-term goals

c. if we write down the dates

d. if we put forward some plans

2. New short-term goals are built upon_.

a. two years

b. long-term goals

c. current activities

d. the goals that have been completed

3. When we complete each step of our goals,

a. we will win final success

b. we are overwhelmed

c. we should build up confidence of success

d. we should strong desire for setting new goals

4. Once our goals are drawn up,

a. we should stick to them until we complete them

b. we may change our goals as we have new ideas and opportunities

c. we had better wait for the exciting news of success

d. we have made great decision

5. It is implied but not stated in the passage that

a. those who have long-term goals will succeed

b. writing down the dates may discourage you 
c. the goal is only a guide for us to reach our destination

d. every should have a goal

\section{ApPEndix C. The QuestionnAIRE}

1. Is it important of cooperative learning in English reading teaching?
A yes
B no
C not care

2. Do you like cooperative learning in English reading?
A yes
B no
C not care

3.Is cooperative learning useful for English Learning?
A a lot
B little
C no

4.What do you think of your reading speed?
A fast
B just so so
C slow

5.What do think of your English comprehensive ability?
A great
B just so so
$\mathrm{C}$ bad

6.What do you think of your classroom atmosphere during English teaching?
A harmonious
B disorder
C nervous

7.What is your degree of confidence in English reading?
A confident
B just so so
C no

8. What is your feeling while reading?

A express and listen B just listen C no expressing

9.What do you do when listening other's ideas?

A listen seriously B listen sometimes C no listening

10.How do you behave in English class?

A positive $\mathrm{B}$ passive $\mathrm{C}$ have to

APPENDIX D. THE OPEN INTERVIEW

Interview Questions

During cooperative learning, are there any problems in groups and does it behave in which ways?

\section{REFERENCES}

[1] Beasley,W.(1996). Book Review: Cooperative Learning. ELT Teaching, (2):55-58.

[2] Cai,H.P.\& Cai,M.D.\& Luo,Y.(2005).The Application of Cooperative Learning in English Teaching. Beijing: Capital Normal University Press.

[3] Ding,G.F. (2005). The Basic Trend of Cooperative Learning and Research. Journal of Nanjing Normal University,(07):11-15.

[4] Gao,X.B. (2005). Moving to Collaborative Learning. Shanxi: Shanxi Education Press.

[5] Sharan, S. (1992). Cooperative Learning: Theory and Research. New York: Praeger Publishers.

[6] Hymes, D. (1972). On Communicative Competence. Harmondsworth: Penguin.

[7] Johnson, Johnson and Holubec. (1993). Circles of Learning: Cooperation in the Classroom. Beijing: Foreign Language Teaching and Research Press.

[8] Krashen, D. (1981). Second Language Acquisition and Second Language Learning. Oxford: Pergamon Press.

[9] Lian,X.H. \& Wang, Y.H. (2003). The Application of Cooperative Learning Principle in English Teaching. Foreign Language Teaching, (2): 44-46.

[10] ]Pan,G.B. (2003). The Theory and Practice of Cooperative Learning. Beijing: Kai Ming Press.

[11] Pei,D.N.(1998). Developing Teaching. Shenyang: Liaoning People Press.

[12] Pei,D.N.(2000).The Teaching Strategy of Cooperative Learning-Developmental Teaching Laboratory Research Report. Subject Education, (02): 22-27.

[13] Shi,M.Z. (2006). A Comparative Study of Sino-US Cooperative Learning. Sichuan: Sichuan Normal University Press.

[14] Slavin, R.E. (1987). Cooperative Learning: Review of Educational Research. Needham Heights, Massachusetts: Allyn \&Bacon.

[15] Wang,L. (2001). Cooperative Learning - Principles and Strategies. Beijing: Academy Press.

[16] Wang,Q. \& Cheng,X.T. (2000). English Teaching Course. Beijing: Higher Education Press.

[17] Zeng,Q. (2002). Reflection and Prospect of Cooperative Learning Research. Educational Theory and Practice, (03):25-29.

[18] Zhang,F.K. \& Zhao,T. (2004). The Application of Cooperative Learning Theory in College English Reading Teaching. Foreign Language World, (06):43-47.

Yayan Yu was born in Linfen, China in 1992. She received her bachelor's degree in English teaching from Yuncheng University, China in 2016. Her research interests include English teaching and linguistics.

Ms. Yu got a second prize scholarship and a prize of excellent student during the study for a master degree. 